\title{
Vinho e paisagem na perspectiva da sustentabilidade no turismo de Flores da Cunha (RS) na pandemia da Covid-19
}

\author{
Wine and landscape from the perspective of sustainability in the tourism of Flores \\ da Cunha (RS) in the Covid-19 pandemic
}

\author{
Marlei Salete Mecca*1, Suzana Maria De Conto ${ }^{1}$, Thelma Luciana Bebber ${ }^{1}$, Fabrício Fontana \\ Michelon ${ }^{1}$
}

\begin{abstract}
RESUMO
O município gaúcho de Flores da Cunha, objeto da pesquisa, é o maior produtor de uvas e vinhos do Brasil. No contexto da vitivinicultura, a pesquisa procura analisar como a paisagem de vinhedos contribui para a sustentabilidade no turismo do município na retomada do setor durante a pandemia da Covid-19. Na pesquisa de caráter descritivo e qualitativo, utilizou-se de documentos, observação direta e survey. A paisagem da região de Flores da Cunha foi construída em diversos tempos históricos, carregando as marcas da cultura italiana trazida pelos imigrantes. Preponderantemente na paisagem de Flores da Cunha, as vinhas são cultivadas pelo sistema de condução em Pérgola ou Latada, conferindo ao município uma paisagem única. No período da pandemia ocorreu aumento do consumo de vinho nacional que impulsionou o interesse dos consumidores em conhecer as vinícolas e os vinhedos. Com a retomada do turismo evidencia-se um interesse maior dos turistas pelos vinhedos e suas paisagens, principalmente pela possibilidade de usufruir desses espaços ao ar livre e sem aglomerações. Esse interesse dos turistas por conhecer os vinhedos, as paisagens e os produtos secundários da uva, valorizam a produção local e potencializam a sustentabilidade.
\end{abstract}

Palavras-chave: Paisagem; Pandemia da Covid19; Sustentabilidade; Turismo; Enoturismo.

\begin{abstract}
The city of Flores da Cunha, object of the research, is the largest producer of grapes and wines in Brazil. In the context of vitiviniculture, the research seeks to analyze how the landscape of vineyards contributes to sustainability in tourism in the city in the recapture of the sector during the Covid-19 pandemic. In the descriptive and qualitative research, documents, direct observation and survey were used. The landscape of the Flores da Cunha region was built in various historical times, bearing the marks of Italian culture brought by the immigrants. Predominantly in the landscape of Flores da Cunha, the vineyards are cultivated by the conduction system in Pérgola or Latada (horizontal system), giving the city an unique landscape. During the pandemic period, there was an increase in national wine consumption, which boosted the interest of consumers in getting to know the wineries and vineyards. With the upturn of tourism, a greater interest of tourists in the vineyards and their landscapes is evident, mainly due to the possibility of enjoying these spaces outdoors and without agglomerations. The interest of tourists in getting to know the vineyards, landscapes and secondary products of the grape, values local production and enhances the sustainability.
\end{abstract}

Keywords: Landscape; Covid-19 Pandemic; Sustainability; Tourism. Wine tourism. 


\section{INTRODUÇÃO}

O vinho é parte integrante da experiência humana há quase setenta séculos. Apesar de suas origens serem incertas, ele tem sido produzido e consumido onde quer que uvas ou variedade de frutas cresçam. Em razão da ampla variedade disponível de vinhos e da complexidade de aromas, essa bebida está carregada de simbologia. Para algumas pessoas, o vinho é uma bebida simples, barata, que vem em uma jarra e é consumida com refeição diária; para outras, trata-se de uma bebida cara e misteriosa, apreciada apenas algumas vezes por ano, em ocasiões especiais. Essas ideias contrastantes influenciaram o desenvolvimento do vinho no curso da história e continuam a influenciar seu lugar no mundo. (Henderson \& Rex, 2012).

A cultura do vinho, conforme Marc e Castilho (2004), nasceu com a evolução das civilizações mais antigas, apresentando uma cultura milenar no cultivo da vinha e no acaso da descoberta do vinho, resultado da fermentação espontânea do suco de uva que provavelmente ocorreu pelo esquecimento das uvas em algum tipo de recipiente, levando o homem primitivo a transformar o produto natural da vinha, a uva em vinho

Uma influência importante do início do comércio de vinho e da difusão de uvas era seu uso nas práticas e cerimônias de diferentes religiões. Nas pregações religiosas requeriam que o vinho estivesse disponível. Isso complementou os mercados de consumo do vinho. $\mathrm{O}$ vinho e as plantas das uvas se moveram junto com as rotas de comércio e com os missionários (Sommers, 2010, p. 142).

Tanto Gregos quanto Romanos se apropriam da cultura da vinha e do vinho ao cultuarem Deuses, dado a importância que a videira e o vinho representavam em suas civilizações, segundo Dardeau (2013), na Grécia antiga, o Deus Dionísio, foi o responsável pelas festas e ciclos da vinha e do vinho, já para os Romanos, Baco representava o criador do vinho.

Para Rabachino (2007), o desenvolvimento do cultivo da videira e a consequente produção de vinhos se dá pelas obras de irrigação e canalização das águas do Rio Nilo pelos Egípcios e assim ele substitui o consumo de outras bebidas como o Hidromel (bebida alcoólica provinda do mel). Segundo Dardeau (2013), em 1922 uma descoberta na tumba do Faraó Tutankamon (1371-1352 a.C.) foram achadas 36 ânforas de vinho, com o que podemos denominar de rótulo pois contavam com as informações de ano de produção, local de produção e nome do vinhedo. 
No Brasil, inúmeras tentativas em diversos períodos se estabeleceram para o cultivo de vinho, segundo Dallanhol e Tonini (2012) "apenas após a chegada dos imigrantes italianos na Serra Gaúcha, a partir de 1875, que o cultivo da uva, naquele momento do tipo Isabel - adquiriu expressão.” Ainda de acordo com as autoras Dallanhol e Tonini (2012, p. 36):

Devido ao clima e à geografia do Sul e, especialmente, da Serra Gaúcha, o Estado do Rio Grande do Sul foi se tornando o principal produtor de uvas e vinhos do País, onde os imigrantes italianos puderam retratar parte da sua cultura simbolizada inclusive pela importância que o vinho possui no dia a dia. A história do vinho no Brasil perpassou, necessariamente, por inúmeros acontecimentos no estado gaúcho, o que ocorre até hoje. O setor foi se solidificando e muitas ações foram realizadas.

A Serra Gaúcha, é a macroregião mais tradicional, berço da viticultura brasileira, onde foi encaminhado o maior número de imigrantes italianos, chegados no Brasil a partir de 1875 . Está situada a $29^{\circ}$ de latitude sul, entre 400 e 700 metros de altitude. Apresenta noites temperadas e frequentemente, elevada umidade. As temperaturas médias ficam entre $16^{\circ}$ e $18^{\circ} \mathrm{C}$. Apesar de não ostentar as melhores condições climáticas, nem a melhor topografia, para o cultivo de videiras, a Serra Gaúcha, é a macrorregião brasileira que se pode considerar domada. (Dardeau, 2013 p. 199).

No berço da vitivinicultura Brasileira encontra-se Flores da Cunha que está localizada na serra gaúcha, a $150 \mathrm{~km}$ de distância de Porto Alegre, capital do estado do RS e a 17 km de Caxias do Sul, principal cidade da região. Segundo IBGE (2020), a população estimada do município é pouco mais de 31.063 habitantes em uma área de $273,673 \mathrm{~km} 2$.

De acordo com o site oficial do município, sua fundação remonta ao ano de 1876, foi colonizada por imigrantes italianos, oriundos especialmente do Norte da Itália. A emancipação do município ocorreu em 1924. Até 1935 o município de Flores da Cunha era denominado de Nova Trento, foi devido a uma homenagem ao então governador do estado General José Antônio Flores da Cunha que houve a mudança do nome da cidade.

Dentre as características que marcam o município de Flores da Cunha, é de especial valor a preservação dos saberes e dos fazeres dos colonizadores e seus descendentes. Flores da Cunha é o município com maior produção de vinhos e uva do país, o segundo pólo moveleiro e o primeiro produtor de bebidas alcoólicas do estado. De acordo com a Revista Perfil Socioeconômico de Flores Cunha (2019) uma das características da região são as plantações de videiras em pequenas propriedades rurais, 
em Flores da Cunha, 43,65\% das propriedades rurais possui de 1 a 10 hectares, e 53,91\% de 10 a 50 hectares, totalizando 4.784 hectares de uvas plantadas no ano de 2018. Segundo o site oficial do Município (2020), Flores da Cunha possui em torno de 200 indústrias vinícolas (desde pequenas cantinas rurais a grandes empresas vinícolas), produzindo 120 milhões de litros de vinho.

A produção de uva na safra de 2020 no Rio Grande do Sul, de acordo com a Secretaria da Agricultura, Pecuária e Desenvolvimento Rural (2020), foi de 504.898.058 de quilos, sendo 101.890.426 quilos de uvas viníferas e 403.007.632 quilos de uvas americanas ou híbridas. A safra 2020 apresentou um aumento na elaboração de vinhos finos e de mesa, quando comparado a safra 2019. Sendo que o maior aumento foi observado na elaboração de vinhos tintos de mesa, que representou um aumento de $51 \%$ quando comparado à safra 2019, e a elaboração de vinhos rosados finos, com um aumento de $40 \%$ à safra 2019. A produção de sucos de uva apresentou um aumento de 60,7\% quando comparado à safra de 2019.

A vitivinicultura faz parte do desenvolvimento do turismo no Município de Flores da Cunha. Conforme Molon (1996) diante do crescimento da produção das uvas e dos vinhos no município de Flores da Cunha aconteceu, no período de 26 de fevereiro de 1967 a 12 de março de 1967, a $1^{\circ}$ FenaVindima, festa que consagrou a uva como o principal produto agrícola dos Florenses. A FenaVindima, que ocorre a cada quatro anos, teve sua décima quarta edição em fevereiro de 2020.

Nesse contexto da vitivinicultura, a pesquisa procura analisar como a paisagem de vinhedos contribui para a sustentabilidade no turismo do município de Flores da Cunha na retomada do setor durante a pandemia da Covid-19. A metodologia para o desenvolvimento da pesquisa foi descritiva e documental com utilização de survey e abordagem predominantemente qualitativa.

\section{REVISÃO DA LITERATURA Paisagem}

A paisagem, como imbricação entre o cultural e o natural, diferente do território que abarca outras questões mais amplas, se apresenta como uma marca que o grupo imprime na superfície terrestre, e cuja grafia, ao mesmo tempo, o reflete; e se apresenta como matriz, porque participa dos esquemas de percepção, concepção e ação (Berque, 1998). 
Assim, em ampliação, a palavra começa a designar um conjunto de terras sob a ação de uma coletividade social, congregada por relações familiares e culturais, e por tradições de defesa comum e de solidariedade na exploração de seus produtos (Silva, Pons \& Valduga, 2016). Tonietto (2007) abrange mais ao colocar que além dos aspectos do meio natural [clima, relevo, solo, água], os fatores humanos de produção incluindo a escolha das variedades, aspectos agronômicos e aspectos de elaboração dos produtos são indispensáveis para se pensar o terroir.

Segundo Castrogiovanni (2002, p. 65), a paisagem é a unidade visível do território, “[...] possui uma identidade visual, caracterizada por fatores de ordem social, cultural e natural, contém espaço e tempo distintos - o passado e o presente -, ou seja, um acúmulo de tempos desiguais.”. Assim, a paisagem é colocada como resultado da ação da cultura sobre a natureza.

Berque (1998) introduz a discussão da paisagem-marca e paisagem-matriz. A qual a marca está expressa na coletividade e a matriz nos esquemas de percepção, de concepção e de ação que canalizam, em certo sentido, a relação com o espaço e a natureza. Nessa perspectiva, todas as paisagens contêm significado simbólico, visto que são o produto da apropriação e transformação do meio ambiente pelo homem, no qual foram impressos traços culturais e simbólicos de cada grupo (Cosgrove, 1998). A paisagem participa do sistema de valores humanos, definindo relacionamentos complexos entre as atitudes e a percepção sobre o meio, o que leva a uma relação afetiva do sujeito com seu meio (Costa, 2010).

Segundo Andreotti (2012), a paisagem não pode estar separada do homem. O homem marca a paisagem com sua cultura e por ela também é marcado; a paisagem é resultado da história e das práticas encontradas na comunidade.

A paisagem vitícola, foi construída no espaço-tempo, fruto das relações sociais dentro do processo histórico na formação e ocupação do território da Serra Gaúcha pelos imigrantes italianos, agente fundamental para consolidação da paisagem de vinhedos. A paisagem inicial encontrada pelos imigrantes foi mata nativa densa, que na construção do território foi sendo substituída pelos atores do passado, sendo uma sobreposição de outras paisagens conforme Santos (1997 p. 84) a paisagem existe, através de suas formas, criadas em momentos históricos diferentes, porém coexistindo no momento atual.

O meio geográfico dos quais os vinhos derivam é o que determina a sua origem, incluindo os fatores naturais e humanos. Nessa definição, as características e as 
qualidades do território [terroir] é o que diferencia cada produto e/ou serviço que derive desse meio geográfico. Essas denominações garantem a diferenciação produtiva de acordo com o regional, visto que, mesmo com os anseios globais em homogeneizar, não há territórios iguais e, portanto, nem paisagens (Tonietto, 2007).

A paisagem com recurso turístico, foi considerada na declaração Cultural da UNESCO,1992. Considera-se paisagem cultural, as diversas interações que ocorreram no território mediante as interações dos diversos grupos sociais no meio ambiente, e a paisagem como transformação das relações humanas no estabelecimento de sua identidade cultural, portanto o território do vinho é formado por elementos materiais/tangíveis ou imateriais/intangíveis.

Em consonância com a Unesco, o Iphan regulamentou a paisagem cultural como instrumento de preservação do patrimônio cultural brasileiro em 2009, por meio da Portaria n 127. Como definição, a chancela de Paisagem Cultural Brasileira é uma porção peculiar do território nacional, representativa do processo de interação do homem com o meio natural, à qual a vida e a ciência humana imprimiram marcas ou atribuíram valores.

Para Medeiros (2018), a tradição, os saberes e a cultura da uva e do vinho resistem e são patrimônio. O Território do Vinho da Serra Gaúcha, portanto já se encontra na luta pela preservação de seu patrimônio, e se constitui um território de resistência cultural e patrimonial. Ainda segundo Medeiros (2015) o território é um espaço cultural e também político que atende as articulações políticas, econômicas e sociais. O turismo pode se apropriar da valorização do patrimônio, onde o vinhedo transformou a paisagem demarcando esse território pelo viés da colonização italiana, tornando-o marca identitária da cultura da uva e do vinho no Brasil.

Para Dall Pizzol e Pastor (2016 p. 28):

Uma questão prática voltada para fomentar o turismo do vinho nessa região vitivinícola trata de estudar a paisagem do vinhedo como atrativo turístico. Dessa forma, a visitação às empresas vinícolas, que atualmente passa a ser uma das motivações mais evidentes entre os visitantes, deverá ser sempre considerada um elemento essencial.

Segundo Beni (2004), o processo de globalização acaba por deixar todos os destinos turísticos muito parecidos, uma forma de mercantilização da experiência do turista, por outro lado cabe às cadeias do turismo inovar e promover áreas antes ignoradas, diversificando os serviços e os atrativos do destino; oferecendo experiências únicas e especiais aproveitando os recursos como diferenciação do território, um desses recursos é o próprio patrimônio natural e cultural que o destino oferece e que o turista quer não 
apenas ver, mas experienciar e compartilhar sua experiência memorável [...] estimular a atenção, o "olhar", o sentimento, a emoção, as sensações e as percepções [...] o maior diferencial continua sendo a contribuição específica dos singulares recursos naturais, físicos, humanos e culturais de um destino.

\section{Um pouco da história das videiras no Brasil}

Segundo Dall Pizzol e Souza (2014) o tratado de Tordesilhas (1494) dividiu o território entre espanhóis e portugueses, cabendo aos espanhóis a povoação do território gaúcho através das missões jesuítas. O território foi palco de inúmeras batalhas e em 1750 assinam um o tratado de Madri, onde os portugueses deram a colônia de Sacramento (Uruguai) aos espanhóis e em troca recebem a região formada pelos 7 povos das missões. As origens históricas enquadram o Estado nesse contexto vitícola hispano-americana, ora pelo seu domínio espanhol ora pelo português, ambos com conhecimentos na cultura da vinha e do vinho, mas, conforme Dallanhol e Tonini, 2012:

Com a vinda dos portugueses para o Brasil em 1500, as videiras foram introduzidas no País, trazidas da Ilha dos Açores, em 1532, pelo colonizador Martim Afonso de Souza, no mesmo período o português Brás Cubas realizou tentativas de cultivar a vinha no litoral paulista, e logo depois, nos arredores de Taubaté.

A questão da videira foi muito problemática pois a Coroa Portuguesa proibiu no período do Brasil Colônia o surgimento de indústrias, posteriormente em 1789 D. Maria I, proibiu o plantio das vinhas no Brasil, a preocupação da Coroa era na manutenção do comércio mercantilista da cana-de-açúcar naquele momento e em 1808 D. João VI revoga o alvará de D. Maria. Fato é que as medidas tomadas não impediram as diversas tentativas de cultivo de vinhas na região (Valduga, 2011).

Em 1626, segundo Dall Pizzoll e Souza (2014), o padre jesuíta Roque Gonzalez foi o pioneiro da viticultura gaúcha, o cultivo da videira fez parte da missão evangelizadora e civilizatória das missões. Entre os anos de 1742 a 1773, imigrantes açorianos iniciam uma viticultura com castas portuguesas e francesas. Posterior a 1825 D. Pedro I incentiva o cultivo das vinhas em território gaúcho, mas os alemães se identificaram mais na indústria de suínos e bovinos, a produção de vinhos ficou destinada ao consumo próprio, em contrapartida o alemão Jacob Ruschel, morador da cidade de Feliz-RS teve papel fundamental de fornecer bacelos de videiras aos imigrantes italianos que chegaram a cidade de Nova Milano. Apesar da difusão do vinho ter sido consequência 
inesperada do colonialismo, o mapa moderno da produção de vinho é resultado direto de mais de quinhentos anos de colonização.

Segundo Dall Pizzol e Pastor (2016), na serra gaúcha encontram-se os principais vinhedos do Brasil, e chegam a produzir $80 \%$ da produção do vinho nacional, somado aos vinhos de mesa, vinhos finos, sucos de uva e espumantes. Quanto a forma de plantio das videiras, predomina a formação horizontal nos vinhedos da serra gaúcha, conforme os autores, é estimada em $92 \%$ da área total, o modo de plantação da uva utilizado pelos agricultores que chegaram à serra gaúcha foi o mesmo utilizado no norte da Itália, que era denominado: pérgola trentina ou latada. Isso foi favorecido principalmente pelas condições ambientais aqui encontradas, utilizando as mesmas ferramentas e métodos de trabalho, considerando especialmente o solo, as variedades e o clima do novo território. Ainda segundo os autores, há pouco mais de 140 anos em muitos locais na região, haviam áreas de "bosque impenetrável" devido a força do agricultor essa paisagem foi transformada e humanizada, tendo características únicas no mundo.

Nesse sentido, Dall Pizzol e Pastor (2016) relatam que devido ao grande número de madeira na região e a dificuldade em adquirir arames, as primeiras parreiras usavam madeiras para dar suporte e cobertura às vinhas, além de utilizarem os plátanos na forma de rabicho, onde davam sustentação nas extremidades dos vinhedos, o que deu uma característica única aos parreirais da região.

Preponderantemente na paisagem de Flores da Cunha as vinhas são cultivadas pelo sistema de condução em Pérgola ou Latada (sistema horizontal), conferindo ao município uma paisagem única, já que poucos países conservam esse sistema. Na América do sul encontra pouco representação no Chile, Argentina e no Uruguai. Provavelmente esse método Latada foi seguido em observação as práticas de viticultura levando em consideração a região de imigração da Itália. Na Itália esse sistema apresenta uma pequena variação de nomenclatura, enfatizando zonas setentrionais, exemplos: Pérgulas Trentinas, Pergulas veronesas e pérgulas romagna. A característica principal desse sistema é o de sustentar castas vigorosas que produzem vários cachos de uvas.

Segundo Valduga (2011), a diferença entre os dois métodos de produção é clara. $\mathrm{O}$ vinhedo em espaldeira produz uvas em menor quantidade, mas com mais qualidade, dada a ventilação e exposição ao sol. O sistema latada produz em torno de 3 vezes mais, entretanto, a qualidade é menor. Outras variedades de uvas foram introduzidas e a resistência dos colonos as variedades e ao método espaldeira é visível já que preservar a 
influência do sistema de pergola trentina, da região do Trento na Itália era importante para os descendentes dos imigrantes italianos. Além disso existe o conflito produtivo que se apresenta na paisagem, em decorrência do embate econômica e cultural na paisagem de vinhedos, já que muitos pés de vinhas chegam a ter 80 a 90 anos de idade ou mais. A figura 1 apresenta o plantio em um parreiral no sistema pérgola trentina ou latada e a figura 2 o vinhedo em espaldeira.

Figura 1 - Modelo do parreiral no sistema pérgola trentina ou latada.

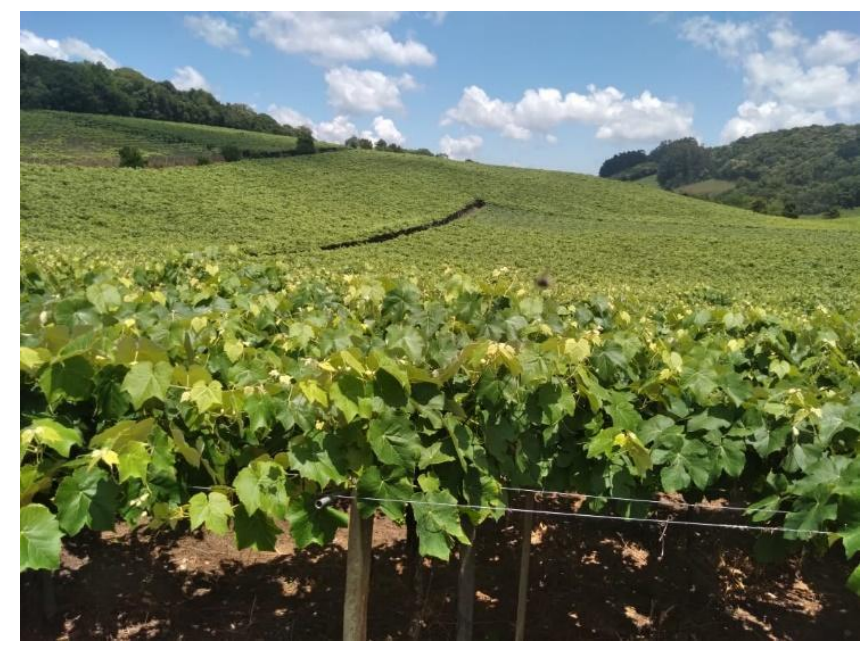

Fonte: Bebber, Thelma (2020)

Figura 2 - Modelo do parreiral no sistema espaldeira.

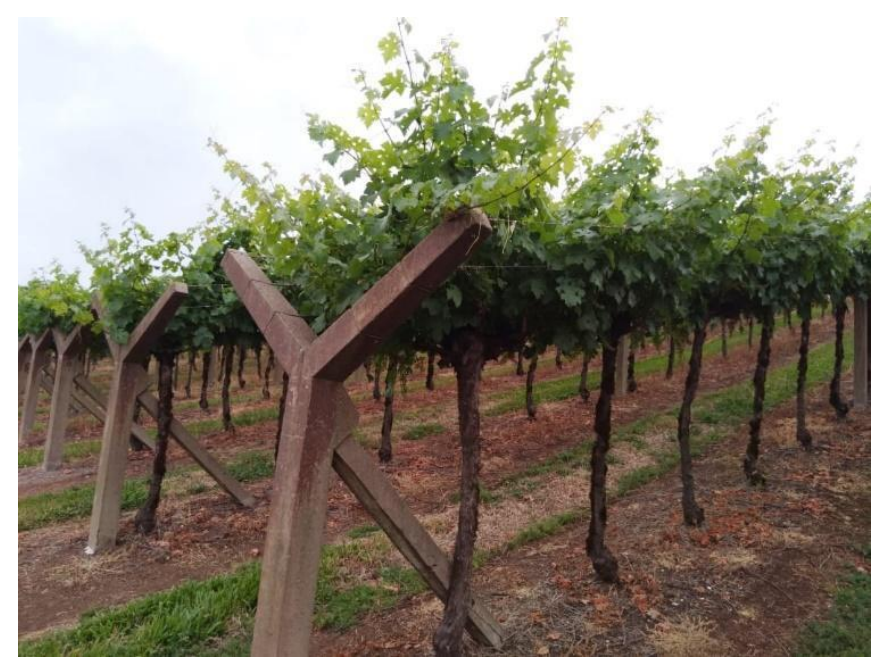

Fonte: Bebber, Thelma (2020)

A paisagem dos vinhedos horizontais vai mudando ao longo das quatro estações, desde um manto verde na primavera, e segue modificando-se ao longo dos meses e por 
fim, as vinhas, sem folhas, apenas apoiada nas estruturas horizontais à vista, o que dá um aspecto de singularidade à paisagem. (Dall Pizzol \& Pastor, 2016). Os autores alertam que o modelo da paisagem caracterizado pelo plantio de uvas no sistema pérgola trentina ou latada pode estar à perigo devido a novas formas de plantio e que os certificados de Indicação Geográfica são ferramentas importantes para preservar essas paisagens.

\section{Vinhedos e sustentabilidade}

O desenvolvimento sustentável na produção de vinhos é tema importante a ser analisado no enoturismo. A sustentabilidade (social, econômica e ambiental) internalizada na produção e comercialização de vinhos potencializa o turismo regional. A sustentabilidade diz respeito ao "Uso dos recursos, de maneira ambientalmente responsável, socialmente justa e economicamente viável, de forma que o atendimento das necessidades atuais não comprometa a possibilidade de uso pelas futuras gerações.”. (ABNT, 2014).

O desenvolvimento do enoturismo pressupõe o respeito aos princípios fixados para o turismo sustentável, que são assim apresentados pela ABNT (2014):

1. RESPEITAR A LEGISLAÇÃO VIGENTE: O turismo deve respeitar a legislação vigente em todos os níveis no país e as convenções internacionais de que o país é signatário.

2. GARANTIR OS DIREITOS DAS POPULAÇÕES LOCAIS: O turismo deve buscar e promover mecanismos e ações de responsabilidade social, ambiental e de equidade econômica, inclusive a defesa dos direitos humanos e de uso da terra, mantendo ou ampliando, a médio e longo prazos, a dignidade dos trabalhadores e comunidades envolvidas.

3. CONSERVAR O AMBIENTE NATURAL E SUA BIODIVERSIDADE: Em todas as fases de implantação e operação, o turismo deve adotar práticas de mínimo impacto sobre o ambiente natural, monitorando e mitigando efetivamente os impactos, de forma a contribuir para a manutenção das dinâmicas e processos naturais em seus aspectos paisagísticos, físicos e biológicos, considerando o contexto social e econômico existente.

4. CONSIDERAR O PATRIMÔNIO CULTURAL E VALORES LOCAIS: O turismo deve reconhecer e respeitar o patrimônio histórico-cultural das regiões e localidades receptoras e ser planejado, implementado e gerenciado em harmonia com as tradições e valores culturais, colaborando para $\mathrm{o}$ seu desenvolvimento. 
5. ESTIMULAR O DESENVOLVIMENTO SOCIAL E ECONÔMICO DOS DESTINOS TURÍSTICOS: O turismo deve contribuir para o fortalecimento das economias locais, a qualificação das pessoas, a geração crescente de trabalho, emprego e renda e o fomento da capacidade local de desenvolver empreendimentos turísticos.

6. GARANTIR A QUALIDADE DOS PRODUTOS, PROCESSOS E ATITUDES: O turismo deve avaliar a satisfação do turista e verificar a adoção de padrões de higiene, segurança, informação, educação ambiental e atendimento estabelecidos, documentados, divulgados e reconhecidos.

7. ESTABELECER O PLANEJAMENTO E A GESTÃO RESPONSÁVEIS: O turismo deve estabelecer procedimentos éticos de negócio, visando engajar a responsabilidade social, econômica e ambiental de todos os integrantes da atividade, incrementando o comprometimento do seu pessoal, fornecedores e turistas, em assuntos de sustentabilidade, desde a elaboração de sua missão, objetivos, estratégias, metas, planos e processos de gestão.

Foletto, Thomé-Ortiz, Santos e González (2018), ao analisar sobre o enoturismo e a vitivinicultura como alternativa econômica para os produtores rurais do Vale dos Vinhedos no Rio Grande do Sul-Brasil, destacam respostas dos participantes da pesquisa sobre o desenvolvimento do enoturismo: necessidade no aumento da qualidade dos produtos; aumentar o consumo de vinho, garantindo o sustento dos produtores; as famílias devem diversificar sua produção com outros cultivos, não só na vitivinicultura; a vitivinicultura, somada ao enoturismo, trouxe grande desenvolvimento ao Vale dos Vinhedos, gerando novas oportunidades de emprego e de agronegócios; surgimento de pequenas vinícolas, favorecendo pequenos produtores, agregando mais valor nas uvas, consequentemente, gerando emprego para as famílias e outros; surgimento de restaurantes, hotéis e pousadas que trouxeram investidores e pessoas de fora do Vale; aumento do plantio das uvas de mesa in natura e coberta, dando mais renda para os moradores; aumento na produção de suco de uva e geleias; necessidade de preparar melhor os produtores para que tenham condições de enfrentar os avanços tecnológicos da viticultura; com o enoturismo, os produtores podem ampliar a gama de produtos e serviços a ofertar, ligados à cultura da região. Ainda, os autores sinalizam sobre as características dos frequentadores do enoturismo: trata-se de um público diferenciado, que procura por história, gastronomia, vinhos e bem viver.

Borsellino, Migliore, D’Acquisto, Di Franco, Asciuto e Schimmenti (2016) destacam que ainda há falta de uma linguagem comum e compartilhada (técnicas, 
metodologias, indicadores, instrumentos, informações, entre outras) que possam ajudar o consumidor a entender o conceito de sustentabilidade. Ainda, os autores complementam que há necessidade de planejamento e implementação de estratégias de desenvolvimento para o crescimento sustentável do setor capazes de ter em conta tanto os elementos específicos da empresa como a variedade e diversidade dos vários territórios.

Os resultados de Borsellino et al. (2016) ao pesquisar sobre a vinícola Tasca d'Almerita na Sicília, Itália, que foi pioneira na adoção de técnicas sustentáveis, evidenciam que a adoção de métodos produtivos sustentáveis gerou bons resultados técnicos e financeiros para a vinícola, com implicações socioeconômicas positivas também em nível local. As técnicas sustentáveis da vinícola italiana, conforme Borsellino et al. (2016) podem ser destacadas: promoção do território em 1962; diversificação de safras em 1962; defesa da paisagem em 1990; defesa da biodiversidade em 1990; reciclagem de resíduos em 1990; segurança do trabalho em 1995; rastreabilidade das uvas e vinhos produzidos em 1998; purificação eficiente de águas residuais em 1999; minimização do uso de fertilizantes, herbicidas, fungicidas e pesticidas sintéticos em 2010; redução do gasto energético em 2010; capacitação trabalhista em defesa ambiental e sustentabilidade em 2010; redução do consumo de água em 2010; pegada de carbono e de água da empresa em 2011; fontes de energia renováveis (biomassas, fotovoltaica, etc.) em 2011; redução das emissões de gases de efeito estufa em 2011; redução do impacto ambiental no abastecimento corrente em 2012; processos de vinificação sem produtos químicos em 2012 e redução do peso das garrafas em 2012.

Por meio de projetos específicos, Borsellino et al. (2016) comentam que a vinícola pesquisada contribui para a valorização da imagem das áreas onde atua, e mais em geral da própria região, que envolve 16 produtores em um total de 39 sicilianos e simultaneamente fortalece a vocação turística da região por meio da reconstituição de eventos e oferecendo hospitalidade em sua fazenda. No estudo são destacados os motivos que contribuíram para a decisão de produzir vinhos sustentáveis pela vinícola, sendo os seguintes que foram indicados: escolha ética; presença de demanda do consumidor por produtos sustentáveis; proteção da biodiversidade; subsídio público por meio de Programa de Desenvolvimento Rural no período de 2007-2013 para a Sicília; produto de maior qualidade; melhor controle da gestão da empresa e diferenciação para a os concorrentes. 
Nesse sentido, Ramos, Cuamea e Galván-Léon (2019) destacam a importância de as vinícolas desenvolverem uma estratégia associativa com restaurantes, promovendo a gastronomia da região e atendendo as demandas dos turistas. Os autores sinalizam que isso promove uma distribuição de benefícios econômicos entre outros empresários de alimentos e bebidas, que, por sua vez, vão fortalecer a economia local. Ainda, é destacado no estudo sobre a importância da divulgação da cultural local, onde os empresários do vinho podem promover o artesanato de sua comunidade, divulgando o mesmo durante a visita dos turistas. Como decorrência, os moradores das comunidades do entorno podem obter uma renda adicional para melhorar sua qualidade de vida.

Karagiannis e Metaxas (2020) comentam que em um mercado global conturbado devido à pandemia da Covid-19, as lições dos modelos de cooperação em regiões de enoturismo devem ser consideradas. Regiões famosas nos EUA (Califórnia - Napa) e Europa (França, Itália, Espanha) contam com assistência governamental para marketing e promoção, vendas diretas, rede de varejo organizada e são facilitados por suas poderosas marcas globais, o que é uma vantagem. Os autores destacam que após a crise da Covid19, os visitantes provavelmente preferirão destinos menos populares e lotados. Os requisitos básicos das empresas vinícolas em relação ao turismo são a revisão e modernização dos serviços para pessoas com deficiência, famílias e crianças, a introdução de produtos e serviços inovadores, como tecnologia (aplicativos móveis, e-shops e realidade virtual), o aprimoramento da cooperação e a educação continuada da equipe e visitantes.

Em síntese, as contribuições dos estudos evidenciam a diversidade de ações que podem ser desenvolvidas nas cantinas e que estão alinhadas aos princípios do turismo sustentável. O desenvolvimentos do enoturismo de forma sustentável, pressupõe a integração dos diferentes setores de uma comunidade (cantinas, meios de hospedagem, restaurantes, comércio local, entre outros), considerando as demandas e a satisfação dos turistas.

\section{Flores da Cunha - História e Paisagem}

O Município de Flores da Cunha, de acordo com o IBGE possui uma população estimada em 2020 de 31.063 habitantes em uma área de 273,673 km². Segundo o SEBRAE, em 2017 haviam 1.150 propriedades rurais no município, sendo 6,094 hectares plantados, destes $81,2 \%$ representam a produção de uvas. 
O pioneiro no município no desenvolvimento da viticultura, com uvas das variedades Vitis vinífera, foi o empreendedor, João Slaviero. Conforme Dall Pizzol (2014, p. 393), no ano de 1926, Slaviero inicia no porão de sua residência a produção de vinhos com vinhedos próprios da Granja São Mateus, produzindo em sua cantina de nome João Slaviero. Pioneiro também na vitivinicultura, em 1958 funda a João Slaviero \& CIA LTDA. Essa, constituída de 35 sócios, contratou enólogos europeus e aumentou a qualidade dos vinhos. Foi pioneiro no enoturismo buscando tornar o vinho conhecido e criando boa imagem do produto e da marca. No ano de 1961, chegou a produzir 750.000 litros de vinhos e ocupou a $8^{\circ}$ posição no volume em litros de vinhos no Estado do Rio Grande do Sul. Para atender a demanda de turistas de Porto Alegre, São Paulo e Rio de Janeiro, interessados em conferir a extraordinária qualidade de uvas de mesa e os deliciosos vinhos é inaugurado em 1958 o Hotel Otávio Rocha (Molon, 2004).

Conforme Molon (1996) diante ao crescimento da produção das uvas e dos vinhos no município de Flores da Cunha aconteceu, no período de 26 de fevereiro de 1967 a 12 de março de 1967, a $1^{\circ}$ FenaVindima, festa que consagrou a uva como o principal produto agrícola dos Florenses. A festa celebrava a vindima pela mão de muitas famílias de imigrantes que construíram a cidade de Flores da Cunha, dando destaque nacional ao "Vinho".

Com a intenção de dar continuidade ao sucesso conquistado na $1^{\mathrm{a}}$ Feira, ocorre no ano de 1973 a $2^{\mathrm{a}}$ FenaVindima, que recebeu no primeiro dia um público de cerca de 30.000 pessoas (Site da FenaVindima). A $2^{\text {a }}$ FenaVindima coincide com a inauguração da pousada do Galo Vermelho que é o emblemático símbolo histórico do Município de Flores da Cunha. A lenda do galo conta que um mágico, anunciou em seu show cortar a cabeça de um galo e gruda-la novamente, e que nesse espetáculo estaria autoridades como o Intendente e o Delegado que teriam participado como voluntários desse espetáculo. Tudo leva a crer de acordo com Boscatto (1994, p. 72), que a estória do galo é inverídica.

A marca, em 1973, da hospedagem na "Pousada do Galo Vermelho", segundo Lopes (2016) foi o luxo, sendo referência para casais de todo o Brasil passarem a Lua de Mel, empresários, políticos e artistas como a atriz Florense muito famosa Maria Della Costa, que também contribui na divulgação das festas com a imagem pública. A Pousada do Galo Vermelho tornou-se referência, não somente no Rio Grande do Sul, mas em todo o Brasil. Na época, recebiam pessoas de Caxias do Sul, Novo Hamburgo, São Leopoldo, Porto Alegre, Rio de Janeiro, São Paulo, do Nordeste, enfim, a diversidade de público era 
muito

grande.

Kunz, era um visionário, acreditava que o turismo motivado pela busca do vinho ajudava a fixar mão de obra na área rural e trazia retorno financeiro tanto quanto produzir uvas, além de ser um turismo limpo sem aglomeração e sem agressão a natureza, pelo contrário ajudava a preserva a natureza e o patrimônio dos vinhedos. E que a singularidade da região diante de seus recursos naturais e sua beleza exuberante, clima ameno e a hospitalidade local criavam o ambiente perfeito para atrair turistas, motivados em conhecer um pouco mais da cultura italiana. Porém, em 1982, o hotel fecha suas portas. A Whiskeria, que também era de Kunz, é vendida para a Bebidas Fante que mantiveram os produtos clássicos de Kunz em sua linha de produção, Sang'Galo e Whisky Cokland.

A FenaVindima se manteve e em 1987 comemorou seus 20 anos, dentre os destaques do evento, o corso alegórico contou com 31 carros que retrataram os costumes e as tradições da comunidade. Em 1990 um público de 60 mil visitaram o evento. Como destaque a Feira ocorrida em 1995 trouxe o jingle da festa que exaltou a história do galo e até hoje está na memória de muitos florenses. Em 1999, na Feira, mais de 100 mil pessoas visitaram o evento. Ainda, na Feira em 2003 a APROMONTES (Associação dos Produtores dos Vinhos dos Altos Montes) apresenta pela primeira vez seu roteiro turístico composto por 12 vinícolas, enaltecendo o enoturismo. Em 2007 a Feira comemorou seus 40 anos com o tema Retratos de Nossa História, o evento buscou resgatar essa trajetória e trouxe em um dos carros alegórico, a atriz Maria Della Costa, que voltou a cidade para uma homenagem. Em 2011 a Feira teve como proposta central contar a evolução gastronômica do município, desde os primeiros alimentos, passando pelo menarosto até a alta gastronomia. Em 2015 a Feira quis valorizar aspectos da festa e não somente de uma feira comercial. Os visitantes puderam vivenciar os costumes e as tradições, foram vendidas mais de 7 mil refeições no Festival do menarosto. Em 2020 a $14^{\text {a }}$ FenaVindima retratou as vivências e experiências únicas que a festa oferece. Música, cultura, dança, trabalho, gastronomia, vindima, artesanato, tradição, além da uva e do vinho, foram os elementos principais da festa. Soma-se a isso a união dos povos e migrantes que forjam a pujança da Flores da Cunha e fazem da FenaVindima 2020 "A Festa de todas as mãos" que recebeu cerca de 100.000 visitantes.

Atualmente a cidade se reestrutura com novos roteiros, o recente Otávio Rocha Vila Colonial, localizado no distrito de Otávio Rocha, que nasceu com experiências 
rurais, gastronomia, vinho, patrimônio cultural com visitação em Igreja, Museu e o Restaurado Casarão Veronese, o renascimento da localidade foi possível pelo engajamento da população local e do sebrae para reestruturação da localidade. Em outro ponto de Flores da Cunha no travessão Alfredo Chaves, os empreendedores trabalham para lançar um novo destino enoturístico que envolve não apenas a localidade de Alfredo chaves, mas os parceiros do entorno, com a cidade vizinha de Nova Pádua e do Travessão Martinho em Flores da Cunha. Esse roteiro a princípio será chamado de Caminhos de Alfredo: enoturismo rural, e será composto por uma diversidade de empresas voltadas para o turismo do vinho, suas vinícolas, varejos e restaurantes, hospedagem, agroindústria de sucos e geléias, cacharias e produção de prosciutto inspirada na cultura italiana.

\section{METODOLOGIA}

A pesquisa classifica-se em relação aos procedimentos técnicos como documental complementada com survey. Em relação ao objetivo como descritiva com abordagem qualitativa.

Segundo Gil (2002) a pesquisa documental vale-se de materiais que não receberam ainda um tratamento analítico, ou ainda que podem ser reelaborados de acordo com os objetos da pesquisa. A pesquisa documental tem a finalidade de reunir, classificar e distribuir os documentos de todo gênero dos diferentes domínios da atividade humana, e é assim considerada quando elaborada a partir de materiais que não receberam tratamento analítico (Pereira, 2019).

A pesquisa survey, segundo Gil (2011) visa interrogar diretamente as pessoas cujo comportamento está sendo estudado. Consiste na solicitação de informações a um quantitativo significativo de respondentes sobre a problemática estudada. Para Pinsonneault e Kraemer (1993) a survey se caracteriza como procedimento de pesquisa onde os dados são obtidos junto a uma população-alvo, normalmente, via questionários.

De acordo com Köche (2016, p. 124), a pesquisa descritiva é caracterizada por estudar as relações entre duas ou mais variáveis de um fenômeno sem manipulá-la. Guth (2007, p. 46), salienta que a pesquisa descritiva tem a finalidade de estudar as características especificas de um grupo.

As técnicas qualitativas focam a experiência das pessoas e seu respectivo significado em relação a eventos, processos e estruturas inseridos em cenários sociais (Skinner, Tagg \& Holloway, 2000). 
A pesquisa qualitativa segundo Guth (2007, p. 74), “é caracterizada por não empregar um instrumento estatístico como base no processo de análise do problema", desta forma o emprego se dará através de qualidades especificas do estudo de caso.

\section{Procedimentos de coleta e análise dos dados (Thelma)}

A pesquisa foi direcionada aos visitantes da Vinícola Família Bebber, localizada na Rota do Travessão Alfredo Chaves em Flores da Cunha. A vinícola é considerada uma vinícola Boutique. A mesma foi premiada por três anos consecutivos na Avaliação Nacional de Vinhos que acontece anualmente em Bento Gonçalves: melhor vinho tannat varietal entre 16 melhores vinícolas do Brasil e com outros cinco vinhos entre os $30 \%$ mais representativos no ano de 2020. A produção da vinícola atinge um público bem segmentado do mercado brasileiro que busca por qualidade.

A coleta de dados foi realizada no período de 26 de outubro a 6 de novembro de 2020. A pesquisa alcançou os turistas que visitaram o Município de Flores da Cunha no feriado do dia 2 de novembro. Foram coletados 61 contatos de visitantes que estavam agendados em grupos distintos de degustação e obteve-se retorno de 39 respondentes representando $63,93 \%$.

Para a coleta de dados, foi realizado o primeiro contato por telefone informando sobre a pesquisa e convidando para a participação. Na sequência, foi encaminhado por Whatsapp o link da pesquisa. No roteiro de perguntas constam informações referentes à cidade de origem; se era a primeira vez que visitava o roteiro enoturístico (turismo de vinho) de Flores da Cunha; quais foram os meios de transportes utilizados para conhecer a cidade; o que motivou a viajar ao roteiro enoturístico durante a pandemia da Covid-19; qual foi a experiência no roteiro turístico em relação à Paisagem dos vinhedos, vinícolas, vinhos e atrativos da região e, por último, questionou-se sobre o que os turistas gostariam de vivenciar em um roteiro enoturístico (turismo de vinho) que envolvam experiências em espaço aberto. 


\section{ANÁLISE E DISCUSSÃO DOS RESULTADOS}

Referente aos estados de origem dos respondentes destaca-se: São Paulo $(33,3 \%)$; Rio Grande do Sul (28,3\%), Rio de Janeiro (15,4\%), Santa Catarina (7,6), Ceará $(7,6 \%)$, Goiás $(5,1 \%)$ e Paraná $(2,7 \%)$. Importante observar que a maioria $(66,66 \%)$ são novos visitantes e 33,33\% já haviam visitado a região. Evidencia-se que os turistas de São Paulo são oriundos de diferentes cidades do interior do estado.

Apesar da região de Flores da Cunha ser o maior produtor de vinhos do Brasil, ainda é um destino pouco divulgado. De acordo com a Associação Brasileira de Enologia, o aumento do consumo de vinho foi motivado pela variação de câmbio, motivando a busca por rótulos nacionais locais, favorecendo, com isso, a divulgação dos produtos e produtores nacionais. O maior número de respondentes, vindo do Estado de São Paulo, utilizaram o transporte aéreo, destacando-se a facilidade do Aeroporto Hugo Cantergiane, localizado no município vizinho de Caxias do Sul, onde não há a necessidade de conexões com outros aeroportos. Os visitantes do Rio Grande do Sul utilizam como meio de locomoção automóvel familiar. Chama a atenção, pela longa distância, que dois respondentes do Estado do Ceará e um do Estado de Goiás, não utilizaram transporte aéreo, optando pelo deslocamento na região com automóvel familiar.

Em relação aos motivos que levaram os turistas a conhecer o destino durante a pandemia de Covid-19, os principais registros estão associados ao vinho, ao enoturismo, a possibilidade de realizar passeios que não implicassem em grandes aglomerações, ao número restrito de pessoas nas vinícolas. Houve preocupação das vinícolas em relação à segurança e ao sentimento de segurança passado aos turistas, já que o turismo de vinho está associado ao contato com a natureza e não está associado ao turismo de massa/aglomerações. As respostas dos participantes em relação as motivações para a viagem no Roteiro Enoturístico são destacadas pelas expressões: "conhecer a região", "curiosidade", "roteiro alternativo ao Vale dos Vinhedos", "cidade pequena" , "lugar calmo", "contato com a natureza", "passeios ao ar livre", "não usar aéreo", "impossibilidade de viajar ao exterior", entre outras. A cidade foi relacionada como nova descoberta, sendo uma alternativa ao Vale dos Vinhedos-Bento Gonçalves -RS, por oferecer turismo de vinho em uma cidade sossegada, pequena, hospitaleira, com beleza natural, com opções de vinícolas, degustações, compras de vinho e com muitas opções ao 
ar livre. A vinícola Família Bebber oferece três espaços diferentes para o visitante: o tradicional varejo onde realiza degustações com no máximo 12 pessoas, um deck externo para degustação ao ar livre e um espaço de degustação guiada pelo enólogo no interior da vinícola com no máximo quatro pessoas para uma experiência exclusiva.

Os relatos sobre a experiência no roteiro turístico em relação à paisagem dos vinhedos, às vinícolas, aos vinhos e atrativos da região, são assim apontados pelos participantes da pesquisa: "maravilhosa", “encantada", "belas paisagens", "paisagens lindas", "paisagens lindas, passeios rurais tranquilos e ótimos para crianças", "belos vinhedos", "bela vista do mirante Gelain", "a paisagem mais linda. Achei a paisagem diferente do Vale dos Vinhedos, os vinhedos são mais amplos". A cobertura dos vinhedos (95\%) no município é pelo método de produção em latada, que dá a idéia de cobertura ampla, citada pelo turista, diferente da paisagem de Bento Gonçalves, plantada em método em Espaldeira. No que tange aos vinhos, as respostas estão relacionadas à qualidade, como "vinhos de muita qualidade", "ótimos vinhos" e "boas surpresas". As vinícolas destacadas, pela hospitalidade e atendimento local, pelos visitantes foram: Vinícola Família Bebber, Casa Venturini, Casa Salvador, Viapiana e Luís Argenta. Um aspecto colocado por alguns respondentes foi em relação à hospedagem, que ainda é deficiente no município.

No questionamento sobre o que os turistas gostariam de vivenciar em um roteiro enoturístico que envolva experiências em espaço aberto, as seguintes respostas são apresentadas: degustação de vinhos ao ar livre $(33,33 \%)$, degustação no interior das vinícolas $(17,94 \%)$, todas as opções $(17,94 \%)$, realizar piquenique nos vinhedos $(15,38 \%)$, participar da colheita da uva $(7,69 \%)$, ter contato direto com o produtor $(2,56 \%)$, ciclismo em meio aos vinhedos $(2,56 \%)$, viver uma experiência holística na paisagem de vinhedos (2,56\%). Ainda, um respondente sinalizou "viver uma experiência holística como meditação, yoga ou retiro espiritual nos vinhedos”.

\section{CONCLUSÃO}

Flores da Cunha, sendo o maior produtor de uvas e de vinhos do Brasil, também apresenta características próprias na paisagem dos vinhedos, caracterizando-se como um diferencial não apenas pela contemplação, como também pela possibilidade de realização 
de passeios de turistas ao ar livre e sem aglomerações. Esse fato conduziu a retomada das atividades das vinícolas em momentos de pandemia de Covid-19. Pelos relatos dos visitantes, foi possível constatar que a paisagem dos vinhedos, aliada a qualidade dos vinhos e dos serviços nas cantinas, contribuem para a sustentabilidade no turismo do município de Flores da Cunha, em especial na retomada do setor durante a pandemia da Covid-19.

Cabe destacar que o sucesso do roteiro do enoturismo para o município de Flores da Cunha depende fortemente das relações que precisam ser continuamente potencializadas pelos produtores locais, proprietários das vinícolas, comunidade local e poder público em prol do desenvolvimento sustentável da região. Nesse sentido, parafraseando Beni (2004) e as respostas dos visitantes (participantes da pesquisa), o roteiro de enoturismo contribui por meio de seus recursos naturais, físicos, humanos e culturais nas experiências memoráveis dos turistas.

Nesse sentido, é importante que as vinícolas desenvolvam, conforme Ramos et al. (2019), estratégias associativas com restaurantes, meios de hospedagem, produtores locais, artesãos, entre outros setores do turismo, promovendo a distribuição de benefícios econômicos e fortalecendo a economia local.

Sugere-se, para trabalhos futuros o desenvolvimento de estudos referentes a práticas de sustentabilidade implantadas nos vinhedos, na produção e comercialização de vinhos; a capacitação de produtores com relação a adoção de tecnologias mais limpas no cultivo da uva; educação ambiental voltada ao enoturismo; critérios de sustentabilidade utilizados por turistas na seleção de roteiros de enoturismo; satisfação de turistas em roteiros de enoturismo do Sul do país; a fatores que influenciam as escolhas de consumo de vinho sustentável; entre outros.

\section{REFERÊNCIAS}

Associação Brasileira de Normas Técnicas - ABNT. NBR 15.401: meios de hospedagem - sistema de gestão da sustentabilidade - requisitos. Rio de Janeiro: ABNT, 2014.

Andreotti, G. (2012). O senso ético e estético da paisagem. Tradução de: FURLANETTO, Beatriz Helena. Ra'e ga, Curitiba, n.24, p.5-17.

Bebber, T. (2020). Registros Fotográficos dos vinhedos de Flores da Cunha. Acervo particular.

Beni, Mário Carlos. (2004). Turismo: da economia de serviços à economia da experiência. Turismo, visão e Ação, 6 (3), set/dez 
Berque, A. (1998). Paisagem-Marca e Paisagem-Matriz: Elementos da Problemática para uma Geografia Cultural. In: Corrêa, R. L., \& Rosendahl, Z. (org.). Paisagem, Tempo e Cultura. Rio de Janeiro: Ed. UERJ.

Borsellino, Valeria, Migliore, Giuseppina, D’Acquisto, Marcello, Di Franco, Caterina Patrizia, Asciuto, Antonio, \& Schimmenti, Emanuele. (2016). 'Green' Wine through a Responsible and Efficient Production: a Case Study of a Sustainable Sicilian Wine Producer. Agriculture and Agricultural Science Procedia, 8, 186 - 192.

Boscatto C. A. (1994). Memórias de um neto de imigrantes italianos. Flores da Cunha: O Florense.

Costa, L. de C. N. (2010). Enoturismo e paisagem cultural: a vitivinicultura em nova proposta. Revista Rosa dos Ventos, 2 (1)

Dall Pizzol, R., \& Pastor, L. V. (2016). Paisagens do Vinhedo Rio Grandense. Bento Gonçalves.

Dall Pizzol, R., \& SOUZA, S. I. de. (2014). Memórias do vinho gaúcho. Porto Alegre, RS: AGE.

Dallanhol, E. B., Tonini, H. (2012). Enoturismo. São Paulo: Aleph. (Série Turismo).

Dardeau, R. (2013). Vinho e Prazer: apreciação de vinhos com um sexto sentido. Rio de Janeiro: Mauad X.

Foletto, Sergio, Thomé-Ortiz, Humberto, Santos, Eurico de Oliveira, \& González, Noe Antonio Aguirre. (2018). Fatores que interferem no desenvolvimento do turismo sustentável no espaço rural do Roteiro Turístico Vale dos Vinhedos, de Bento Gonçalves/RS - Brasil. Gestão e Desenvolvimento, 14(2), p. 204-222, jul./dez. DOI: https://doi.org/10.25112/rgd.v15i2.1252

Flores da Cunha. (2020). Prefeitura Municipal de Flores da Cunha. Recuperado de https://www.floresdacunha.rs.gov.br/secao.php?id=1

Gil, A. C. (2002). Como elaborar projetos de pesquisa. (4 ed). São Paulo, SP: Atlas.

Gil, A. C. (2011). Metodologia do ensino superior. (4 ed). São Paulo: Atlas.

Guth, S.C. (2007). Desmistificando a Produção de Textos Científicos - Com os Fundamentos da Metodologia Científica. São Paulo: Scortecci.

Henderson, J. P., Rex, D. (2012). Sobre Vinhos. São Paulo: Cengage Learning.

Instituto Brasileiro de Geografia e Estatística - IBGE. (2020). Recuperado de https://www.ibge.gov.br/cidades-e-estados/rs/flores-da-cunha.html

Jensen, R. (1996). The Futurist. Washington: May/Jun. 30(3). Recuperado de https://www.academia.edu/18381234/L5_6a_Dream_Society_artikel_af_Rolf_Jensen_P ro_Quest 
Karagiannis, Dimitris, \& Metaxas, Theodore. (2020). Sustainable Wine Tourism Development: Case Studies from the Greek Region of Peloponnese. Sustainability, 12, 5223. doi:10.3390/su12125223 www.mdpi.com/journal/sustainability

Köche, J. C. (2016). Fundamentos da metodologia científica - Teoria da Ciência e Iniciação à Pesquisa. Petrópolis/RJ: Vozes.

Lopes, R. (2016). Memória: Flores da Cunha, um desfile e dois galos. Recuperado de http://pioneiro.clicrbs.com.br/rs/geral/cidades/noticia/2016/03/memoria-flores-dacunha-um-desfile-e-dois-galos-4986380.html

Marc, C., \& Castilho, R. (2004). Larousse do Vinho. Larousse.

Medeiros, R. M. V., \& Lidner, M. (2018). Cultura e Patrimônio, e sua Relação com a Vitivinicultura no Sul do Brasil. Territoires du vin. O Vinho no Brasil. (9) Set. Recuperado de http://preo.u-bourgogne.fr/territoiresduvin/index.php?id=1689

Medeiros, R. M. V. (2015). Território espaço de identidade. In: Saquet, M. A., \& Sposito, E. S. (Orgs.). Territórios e territorialidades: teorias, processos e conflitos. Rio de Janeiro: Consequência.

Molon, F. (1996). FenaVindima. 20 anos: FenaVindima.

Molon, F. (2004). Slaviero, João: Pioneirismo na viticultura gaúcha. Porto Alegre: FM.

Pinsonneault, A., \& Kraemer, K. (1993). Survey research methodology in management informtion systems: as assessment. Journal of Management Information Systems, Automn.

Pereira, J. M. (2019). Manual de metodologia da pesquisa científica. São Paulo: Atlas. Recuperado de https://integrada.minhabiblioteca.com.br/\#/books/9788597008821/cfi/6/10!/4/12@0:0

Perfil Socioeconômico de Flores da Cunha. (2019). Ed. Novo Ciclo - Jornal O Florence.

Ramos, Karen, Cuamea, Onesimo, \& Galván-Léon, Jorge Alfonso. (2019). Wine tourism Predictors of revisit intention to micro, small and medium wineries on the Valle de Guadalupe wine route, Mexico. International Journal of Wine Business Research, 32(1), 22-40, 1751-1062. DOI 10.1108/IJWBR-11-2018-0065

Rabachino, R. (2007). Vocabulário do vinho. Tradução Paola Tedeschi. Caxias do Sul, RS: Educs.

Santos, M. (1997). A Natureza do Espaço: técnica e tempo: razão e emoção. (2 ed). São Paulo: Hucitec.

Serviço de Apoio às Micro e Pequenas Empresas do Rio Grande do Sul - SEBRAE. (2020). Perfil das Cidades Gaúchas: Flores da Cunha. Recuperado de https://datasebrae.com.br/municipios/rs/Perfil_Cidades_Gauchas-Flores_da_Cunha.pdf 
Secretaria da Agricultura, Pecuária e Desenvolvimento Rural do Rio Grande do Sul. (2020). Recuperado de:

https://www.agricultura.rs.gov.br/upload/arquivos/202007/08133156-sisdevin-dadosda-safra-2020.pdf

Silva, R. N., Pons, M. E., \& Valduga, V. (2106). O saber fazer enogastrônomico do território do Vale dos Vinhedos/RS. Revista Ágora, 18(1)

Skinner, D., Tagg, C., \& Holloway, J. (2000). Managers and research: the pros and cons of qualitative approaches. Management Learning, 31(2), 163-179

Sommers, J. B. (2010). Geografia do Vinho. São Paulo: Novo Século.

Tonietto, J. (2007). Afinal, o que é Terroir? Bon Vivant, 8(98). Flores da Cunha

UNESCO - United Nations Educational, Scientific and Cultural Organization. (2008).

Operational Guidelines for the Implementation of the World Heritage Convention.

World Heritage Centre.

Valduga, V. (2011). Raízes do turismo no território do vinho: Bento Gonçalves e Garibaldi,1870-1960. Porto Alegre: UFRGS/PPGGEA.

Recebido em: 05/01/2022

Aprovado em: 05/02/2022

Publicado em: 08/02/2022 